\title{
Learning Womanhood in China
}

\author{
Ma Hongnan \\ Department of Anthropology \\ McGraw Hall \\ Cornell University \\ Ithaca, NY 14853 \\ with
}

\section{ED ROSENBERG}

Department of Sociology and Social Work

Appalachian State University

Boone, NC 28608

SUMMARY Childbirth, a seemingly singular event in China, is nonetheless momentous. Bearing a child transforms a girl into a woman and a mother. Motherhood, in most traditional cultures, symbolizes both the major achievement and the full attainment of femininity. This is particularly true of contemporary China.

Childbirth is "an intimate and complex transaction whose topic is physiological and whose language is cultural" (Jordan 1983:1).

Research is abundant, particularly in this century in the West, regarding the social, cultural, political, psychological, biological, and medical ramifications of childbearing. Most of this research, however, concerns either the practices and customs of highly industrialized Western societies or those of "exotic" cultures considered remote from Western experience (Davis-Floyd 1992; Jordan 1983; Kay 1982; Leifer 1980; Martin 1987; Oakley 1979, 1980). There has recently been concern about reproductive and women's issues in China (Anagnost 1995; Beaver and Schrift 1994, Wolf 1985). But there has been little research on the experience of childbirth itself in China and its implications for Chinese women, who constitute 48 percent of the 1.2 billion inhabitants of the world's most populous nation.

Chinese national history has been chaotic and turbulent in the last two centuries, attracting foreign scholars to the study of its revolutionary political events--but rarely to its domestic and private life. For thousands of years, patriarchal academia in China itself also reflected what was politically significant, rather than the private, personal, or domestic realm of "trivial women's business," as delineated in the precept "The Three Obediences," to father, husband, and adult son. When women lived in perfect conformity, what need was there for research?

In 1955, while Mao Zedong was consolidating his power over the new China as chairman of the Chinese Communist Party, a demographer at Beijing University expressed an opinion that was destined to turn an intense light of political scrutiny and the mustering of all available bureaucratic authority onto the private lives of families and particularly women. In that year, Professor $\mathrm{Ma}$ warned Mao's government of the shadow that unchanged fertility patterns leading to overpopulation would cast upon future Chinese economic development. But the publication of Professor Ma Yinchu's "New Demography" in 1957 was seen as threatening the Maoist revolutionary ideology that glorified a large labor force, and in return earned Ma the dangerous labels of "a Chinese Malthus" and "killer of our revolutionary new blood." 
Ironically, not long after the denunciation of Professor Ma's "counterrevolutionary" demographic perspective, Mao and his colleagues began to realize the importance of population control in China. The lengthiest Chinese political campaign of this century-on population control-was launched in the late 1950 s. Contraception, conception, birth, and abortion, the most intimate experiences of a woman's life, have since taken center stage in the sphere of domestic and international politics, and have thus drawn the attention of the world's scholars. Chinese scholars, who have always walked a tightrope between good research and ideology, have highly celebrated Chinese women's contribution to the solution of the demographic problem in their adherence to the new one-child policy and in their achievement of "national modernization and personal liberation" through the use of birth control pills, intrauterine devices (IUDs), abortion, and sterilization.

However, many Western scholars, joined by human rights organizations and inflamed by accounts of forced late-term abortions and female infanticide, have condemned the one-child policy, succumbing to an ethnocentric misinterpretation of a culture-specific ideological solution. On this issue, the judgment of many scholars and sophisticates is frequently as unsound as that of demagogues and politicians.

In the midst of such ideological debates, moral arguments, and gender-biased perspectives, which exacerbate the tension between the personal and the political, something seems to be lost. Childbirth itself, this most female of human functions, has in the past been painted, if at all, with predominantly masculine strokes.

As we have seen, a recent body of feminist theory has developed in the West, and it includes the notion of a merger between the personal and political.' Material of this kind within the Chinese context is also appearing. ${ }^{2}$ Recently, there has been more interest in the woman's version, an intricate and intimate version-her own version-of learning and growing, of a woman's uncertainties and sentiments, of a woman's delights and dilemmas.

The Chinese womb is indeed "state-owned." 3 Nevertheless, however politicized, Chinese pregnancy and birth are still largely private. While some decision-making power is claimed by the government, the birth experience and its transformations inevitably belong to the woman, her family, and her community. The aim of the following personal narrative is to give voice to the lived experience of a Chinese woman. It is her story that this article traces. She has been considered a number that adds and multiplies. She is a life that reproduces. But she is above all a human being who lives and feels, within the reality given and the reality chosen.

My account attempts to untangle the complicated social, cultural, and political issues surrounding Chinese childbirth. Venturing into this virgin territory uncovers how the threads of ancient memories and the calls of modern dreams chase and dance in the most intimate experience of a Chinese woman today.

\section{Personal Narrative}

Getting $a \mathrm{Job}$

Zhenzhen, I'm pregnant because Weiwei kissed me.

Who told you that, silly girl, you don't get pregnant from being kissed by men, it happens when they touch your breasts.

- Conversation between two college girls in 1987

In the summer of 1990, upon my graduation from college, I got a job teaching English at a university in the city of my birth in northeastern China. 
The New Faculty Orientation Week at the university was packed full, and pretty hilarious. Among the offices we had to visit during the week, the most impressive one, the one we tried to avoid until the last minute, the one we joked about, was the school Family Planning Office.

Many of the new faculty and staff members were fresh from colleges where dating was discouraged and discussion of sex considered an infraction. Ridiculous though it might seem to the non-Chinese, some of us still vaguely believed that a woman would get pregnant if she was kissed or if her breasts were touched. That was the most one would learn from the movies and television programs. Most of us knew very little about sex. The closest I had come to sex education was 30 minutes of biology instruction at my junior high school while studying the "Human Reproductive System" chapter of our text. The two biology teachers for our grade managed to schedule their classes so that the female teacher could have all the girls in her class and the male teacher could have all the boys in his. I never discovered what was taught in the boys' class. In our girls' class, the instruction was highly formal and technical. We learned the names of the female reproductive organs. We also learned that "when the ovulated egg is not fertilized, a woman will bleed and that is called menstruation." It did not sound like anything related to our lives and our personal experience and expectations.

In spite of the constant reiteration of family planning slogans and the publicity billboards that became a part of the national scenery after 1972, real information and hard facts about sexuality, conception, contraception, abortion, and sterilization were almost unavailable to the general population and especially to students.

Yet on the first day of our professional lives, my new colleagues and I were unexpectedly confronted with these intimate issues. We were totally unprepared to discuss "womanhood and motherhood" in a professional setting. Nonetheless, part of our orientation consisted of filling out forms entitled "Family Planning Registration Form," in duplicate, one copy for the school Family Planning Office and the other for our department.

Every state-owned university administrative and academic department appoints a person, usually a married woman with a child, to be in charge of family planning and related routine tasks. Her responsibilities include attending meetings on the latest policies and information regarding family planning and birth control, distributing free contraceptives to married department employees, and writing letters of introduction to higher-level offices on behalf of prospective couples and couples who are ready to have a child. No marriage can be celebrated and no infant can be born without the agreement and approval of this official. These "Family Planning Promotion Directors" (FPPDs), most of whom are kind and helpful, also serve as "big sisters," and lecture on the preparatory basics of sex, particularly conception and contraception. Their instruction style is highly informal, ranging from vague and ambiguous discussions of government policies to whispered snippets of personal experience sprinkled with giggles, sighs, gasps, and surprises.

Many FPPDs are well aware of the sensitive nature of their job and try to avoid behavior that reinforces the stereotypes associated with the "meddlesome granny." Quite a number of the FPPDs, especially those working for the most basic local government organization, the street councils, are either retired woman workers or housewives in the community. Nicknamed "bound-foot patrols," some of those who are over 70 years old still actually have bound feet-which lends truth to the stereotype.

We all filled out the forms, met our FPPDs, listened to the lecture, blushed, and fled. 


\section{Getting Married}

I used to believe that information on sex and sexuality was simply not available in China. Not anymore. I was just not aware of the right access to it-getting married. Getting married introduced me to a new world, but within the same physical setting. No special preparatory work is expected of me except marrying a man, and then I'm embraced and received into my woman associates' secret knowledge bank, which is now open to me. It seems all of a sudden I've earned my membership in the women's club through marrying a man. This exponentially reinforces my feeling of belonging.

Three years after starting my job I was back in the Family Planning Office. My boyfriend and I planned to get married. He was 32 and I was 25 , both well above the late marriage age. All we had to do was to go to our respective FPPDs, get a letter of introduction proving our age, sex, and employment status, and then take the letters to the designated local hospital branch - the District Premarital Physical Examination Center (Hun Jian Suo). Here a physical examination was given (a vaginal exam for women with embarrassing questions about one's virginity and advice on vaginal sanitation). Also, several times a day the Center showed a videotape on sex education. It included an introduction to contraceptive measures. As far as I know, this was a once-in-a-lifetime chance, the only compulsory sex education the majority of Chinese receive. We missed it.

The date we picked for our marriage registration was July 8, 1993, a really auspicious date. Chinese love the numbers eight and 18, which in Cantonese pronunciation are $f a$, meaning "make a fortune," and yao fa, meaning "will make a fortune." The month of July is called qi yue, the seventh (qi) month in Chinese; $q i$, seven, sounds like "together" in Chinese. Therefore, the date we picked sounded like, "We will make a fortune together." Besides, according to the lunar calendar it was May 19, which reads as, "I want it to last forever." 4

On that "auspicious" day, by the time we got all the necessary seals from the department, the work unit, the community council, and the physical examination center (Hun Jian Suo), we were running late. If we stayed for the video we would have had to go to the District Marriage Registration Office the next day. So we talked to the doctor about the possibility of skipping the video and coming back for it another day. He simply told us to go ahead and pay for it anyway. We made it to the Marriage Registration Office before they closed for the day, feeling absolutely exhausted. But we got married, and of course never bothered to go back for the video.

1993 was an eventful year for me. Early in the year I won the championship in the city's English contest. In July I was elected "Young Teacher of the City," and got married. In September we held our traditional wedding. In addition to my university teaching job, I had a part-time position as bilingual training instructor with a U.S. company. I taught two Chinese courses at a Sino-American training center and worked as a translator for the city government. When winter came, my husband and I worked on another task: applying for graduate studies in the United States. We faced a future of wonderful jobs, fabulous opportunities, admirable income, and great promises. Nobody expected us to start a family right away.

My mother asked me a couple of times when we planned to have a baby, and if not soon, what contraceptive measures we were taking. My mother-in-law never inquired. In the first place, back in the 1960s she herself had been a "progressive" professional woman who decided to have only two children; second, she was neither a very demanding nor an inquisitive sort of mother-in-law. 
Finally, her own daughter, a successful architect, was childless and had had two voluntary abortions. I guess my mother-in-law had tried and failed too many times with her, and thus did not try to persuade me.

But I did what she secretly wanted. In retrospect, it would have been surprising if we had not gotten pregnant, since the contraceptive methods we used were condoms and the "natural rule." Our information on contraceptives was gathered from two friends, Ling and Xing.

Ling was a colleague of mine at the U.S. company and a student at the evening English class I taught that semester. We became good friends. She was a very modern professional woman, smart and open-minded. Before I got married she lent me a little pamphlet on the female reproductive system. She shared with me her marital experience, and instructed me on the "seven days before and eight days after [the period]" safe sex rule. It was also from Ling that I learned that one is pregnant if one misses one's period, and why.

Xing was a very close female friend from my high school class. Shortly after I got married she called from Canton, where she is now a housewife married to a Taiwanese businessman. She discussed contraceptive alternatives briefly and told me the story of how she had been on pills, gained weight, and got pregnant twice. She never wanted a baby because she said she was not sure how well she could trust her husband for the rest of her own life and that of the baby. She also hated the idea of pleasing her mother-in-law, a very "old-style Taiwanese lady." Additionally, Xing warned me against IUD use. She said that when she once went for an abortion she heard the most horrible shriek in her life, and later she learned it was a woman whose muscle had grown around her IUD and the doctor was trying to take the IUD out.
Me: Is there any way to be safe?
Xing: $\quad$ Stay away from men.
Me: $\quad$ You're being cynical. Why didn't you tell me that earlier? It's too late now.
Xing: How can I talk about contraception with a girl? You don't need it anyway, have premarital sex.
Me: $\quad$ Thought you never listened to them.
Xing: Well, you're right. So I had to teach myself all this and it's been tough.

\section{Getting Pregnant-An Abortion?}

Definitely, you're pregnant. Go pay at the cashier and wait in the hallway if you need an abortion.

-A nurse

Before long, I missed my period. We first tried the pregnancy test that came with the Newly-Wedded Pamphlet we received on registration day. According to the instructions, "If the blue dot is big and clear, chances are you're pregnant; otherwise, you're not." We never figured out if the dot was blue and round enough. Then I talked to one of my American students, a married woman a couple of years older than me. She gave me one of her own tests. There was indeed something on it, this time a clear red line.

Still in doubt, my husband accompanied me to the hospital for an authoritative test. I had to return to work for the last two hours of the morning, so he stayed on for the result. When I rushed home after my last class he showed me the result, encoded in symbols that did not make sense to a medical illiterate like me.

"What does it mean?" I asked. 
"They said you're probably pregnant."

"What do you mean by 'probably?' They're doctors! What exactly did they tell you?"

Probably pregnant? My brain went blank. It was not that I did not want to be a mother but that I did not know if I wanted to or not because I had not thought about it. I sat there and cried. I was dumbfounded, frustrated, and elated. I did not know how I felt. I decided to go back to the hospital myself.

This was the second time I had ever been to a gynecology department. The first time was that same morning. It took me a while to figure out how to raise the question. I must have looked too hesitant, immature, and unsophisticated to be a "legal" mother.

I showed the nurse my test result. "Would you please interpret this result for me?"

She threw me back a disgusted look. "Positive," she said indifferently.

It still did not make sense to me. My entire hospital experience had been a couple of routine examinations and some penicillin shots. So I had to go back and ask again.

"Would you mind telling me what 'positive' means? Am I pregnant?"

"Definitely, you're pregnant. Go pay at the cashier and wait in the hallway if you need an abortion."

I felt extremely insulted, ashamed, and deflated. My self-esteem was totally gone. I wished I were tough enough to teach her a thing or two. But it had already been the longest day in my life, and bad enough without yet another argument. I muttered a "thank you" and fled. We were endangered, my baby and I; with that careless remark the nurse threatened my dignity and my baby's life.

Reflecting upon my experience with the nurse, I suspect she thought my pregnancy was premarital. For an old lady who had done everything right in her life (I would guess), premarital sex would be immoral and disgusting. I simply could not think of other reasons for her extremely unprofessional and unsympathetic attitude, which bothered me a long time. The good side of it was that it awoke my maternal nature. That was January 6, 1994.

\section{Getting Pregnant-Did I Do It Right? Am I Doing It Right?}

Life is a hard teacher. He gives the test first and then the lesson.

-Traditional saying

I called my mother. "Isn't that wonderful!" she exclaimed. "You should have this baby. Both of you will be too old if you wait till you finish your graduate studies. Don't worry, mom's going to help you with it. From today on eat well, sleep well, and stop worrying, okay? We should celebrate this. My little girl is a woman now and soon she'll be a mom herself."

I told my mother-in-law. It took her a while to respond.

Really? Do you want to keep it? I know you want to go to graduate school. I's up to you, though. But if you decide to keep it, your mom and I will both take care of it. ${ }^{5}$ Your father-in-law and I won't care if it's a boy or a girl. We're not old-fashioned. ... I never wanted to pressure you but a grandchild is a great comfort when people get old, and Jia [my husband] is our only son. Even though you have to leave the baby and go to America, we'll love it and take care of it. Ai, it's never easy for a woman.

As a good mother-in-law, she felt the responsibility of striking the balance between her excitement and my indecision. 
A few days later I had some light bleeding and was not sure whether I should be concerned or not. So I visited my next door neighbor, a woman physician with a two-year-old girl. She was very attentive and helpful.

Neighbor: That can be normal in some cases and abnormal in others. If it gets worse it might be the signal of a miscarriage. Some vitamin $E$ capsules and folic acid tablets should take care of it. If not, go to a doctor. Meanwhile, stay in bed and stay away from cold. ${ }^{6}$ Winter is hard on pregnant women anyway. Did you plan this? You've been married for hardly six months. There's a whole field of science on conception. Usually the quality of the sperm is better after six months because the frequency of a man's ejaculation is probably lower by then. Also, you should have planned your diet before your conception. Eat more protein and vitamins. Of course what you eat contributes to the gender of the baby. Besides, some people believe that February and March are the best months to get pregnant because before that it's pretty much winter, when fresh fruits and vegetables are expensive and those hothouse products are certainly not as nutritious. On the other hand, early spring is the best season to give birth to a baby because babies born in spring are likely to store enough calcium and vitamin $\mathrm{D}$ from the summer for their first winter. Well, it all depends. . .

Me:

Neighbor:

Me: You mean my timing isn't ideal?

Neighbor: Not so bad. See, your first trimester will be January, February, and March, when it's easier to cope with morning sickness. All you have to do is try to eat some walnuts; right now it's the brain development stage in the baby, and walnuts are good brain-builders. Fish and yogurt are also good. Another advantage is that you won't start to show until after spring, so you don't have to wear those big bulky clothes for the two of you. When you do begin to show, you'll be wearing skirts. I've got a friend who's also a teacher. Poor girl, her third trimester fell in winter. At first, she wore her mother's padded pants. ${ }^{7}$ Her mother's a big old lady, you know. Pretty soon she outgrew those pants and had to use safety pins and then a long piece of cotton belt to keep them up. The problem was, she had to run to the bathroom all the time to fasten the pants. It was hilarious, and, of course, terribly embarrassing.

Me: What a nuisance! Don't they sell maternity clothes in the store? I've seen them in foreign movies.

Neighbor: There's one maternity and baby store downtown called the Loving Heart. But all they have are clothes for hot weather. Doesn't help much if you get really big in winter. Plus they are very expensive too. If you're only going to get pregnant once, why bother spending the money?

Gradually and privately I began to celebrate my becoming a woman. Sometimes I was still ambivalent, but I began to relax and slip into my new identity, adding expectant mother to my roles of woman and wife.

One day I went to borrow some reference books on the prenatal stage from a friend who works at a traditional Chinese medicine store. She had a string of questions ready:

Friend: Did you drink that night? Were you in a good mood? Did you quarrel much, around that date? Was your room too hot or too cold? Was your husband smoking those days? Who felt better, you or your husband?

Me: $\quad$ Come on, how do I know which day it was? Spare me, please. The more you ask the less confident I feel. The doctor said it was one of the days near the end of December. Those were probably not good days-we had lots of parties and banquets. ${ }^{8}$ I wish you'd told me all this before I got pregnant. 
Friend: Stupid girl, how could I have talked about all this to a woman with no experience at all! You should've told me that you were planning to get pregnant. Is this your first conception?

Me: $\quad$ Yes, it's my first conception but we never planned it. Did you plan yours? Friend: The first one is usually of good quality. Yes, we planned months ahead. Look at my daughter. Isn't she perfect? She's so smart and beautiful.

Me: $\quad$ Do you mind my asking a question? Did you plan to have a girl?

Friend: We planned on a boy, but actually we' re very happy we' ve got a girl.

"If birthing is like production in our society, then we might as well let it be managed, kept efficient, and eventually be done entirely by machines" (Martin 1987:159). I was almost wishing Aldous Huxley's Brave New World were realized and the Alphas, Deltas, and Epsilons were manufactured on production lines so that we did not have to worry about temperature, dampness, the baby's sex, $I Q$, and appearance. If conception was something so planned that it was artificial anyway, why bother?

One day in mid-January, a childhood friend came to visit. She was a chemist who had married another chemist three months before I got married. The two were applying to an American graduate school and were preparing for the same Graduate Record Exam (GRE) as myself. On learning of my pregnancy, she was surprised and disappointed.

No way. That's going to ruin you. I can't imagine you with a baby. You'll miss your education and all the wonderful things that could happen. You'll become a housewife and a nanny. Come on, we've had too many women sacrificing their youth to a baby and a husband. What happens then? The woman gets old, dependent, and isn't worth a thing. Who cares? You know what? Why don't you abort it? I know of a medicine, Mifeixitong [the Chinese name for a Western medicine]. That's what I had for mine. As long as you're not more than 49 days pregnant it should work. You'll bleed like you do during a period and that's it. You might feel a little sick but it's better than vomiting for months, inflating like a balloon, getting freckles, and becoming a wet nurse. Have an abortion. That's definitely what I'd do if I were you. Having a baby isn't something you do and finish. Having a baby is having a burden for the rest of your life. Think about it.

She had a point, I thought, but she did not convince me. What in the world is a worthy way to live? How can a woman be both nurturing and deserving of respect? Is it possible? Would it not be too taxing?

I tried to discuss it with another friend, Lei, a Malaysian-born Chinese American who was brought up and educated in the United States, and was married to an American. She was at the time residing in China because of her husband's job appointment. Lei is nine years older than me and has had two children already, a six-year-old boy and a three-year-old girl. When she learned that I was pregnant, she sent me a home-baked cake with a congratulations card and shared with me her own story.

Lei: $\quad$ I got my MBA degree, got a job, had a good boss, and wonderful opportunities. Before long I was pregnant. After a lot of struggling, even making "for" and "against" lists, I decided to quit the job and have the baby. It was hard financially, physically, and mentally. But it's proved to be a rewarding choice and I want to have more kids. ${ }^{9}$

Me: $\quad$ But I still want to go to graduate school and get more out of my own life. Both my mother and mother-in-law have promised to help. So....

Lei: $\quad$ You want to bring up your own children. Nobody can be as good as you are for your children. It won't be easy, but God loves us and he's always been there.

Me: $\quad$ But I am not a Christian. 
Lei: [smiling] That makes no difference. He has a purpose in everything. You' re pretty accomplished for one so young. Maybe it's your turn now to learn to be a mother for your baby and a child for the Lord. Don't worry. We'll all pray for you. Things will work out fine.

It felt good to know, in a time of confusion, that God had picked me out and that he would always be with me. But being Chinese, I was not brought up to be a pious Christian, and I unavoidably lacked patience and trust when faced with secular frustrations.

\section{First Trimester-Officialize It}

You have to plan ahead, file an application, get a permit, then try to get pregnant. That secures all possible health care and other benefits for you and your baby.

-My FPPD

I had thought that getting pregnant at age 26, with a 33-year-old husband, would spare us all the tedious paperwork and policy controls. Too optimistic.

When a woman does get pregnant at a "late parturition" age or older, as I did, she has to visit the Family Planning Promotion Department within the first trimester. A letter of introduction, with the couple's names, ages, sexes, marital status, and the approval seals of the work units, must be taken to another government office-the street council, where our work unit was located. In order to get approval from the street council, we had to show our residence booklet, identification cards, and marriage certificate. Once all the documentation was accepted, a "Student Card" would be supplied and a six-hour prenatal education class would be scheduled at a designated hospital.

FPPD: $\quad$ The suggested procedure is, when a couple above the late parturition age plans to start a family, they file an application, get it stamped with seals, obtain a permit, and then try to get pregnant. In practice, this is often embarrassing because people keep checking back with the couple to see if everything's going okay with their efforts to conceive; because of this many people simply reverse the process, just as you're doing. Although there are no legal articles against it, as an FPPD I am supposed to warn people that if this goes on we might have more qualified women getting pregnant than the quota for that year allows. It happens a lot in the countryside but isn't usually a big deal in the urban areas, definitely not in our university. Here, every year we waste some quota because it seems that educated women are more ambitious professionally than family-wise.

Me: What if a woman accidentally gets pregnant before she's old enough?

FPPD: Women who get married before the late parturition age are required to sign a contract promising they won't get pregnant until they are 23 years of age. This contract is secured by a Y500 deposit [about the average monthly income in the university where I taught]. If it does happen earlier and we do have extra quota for that year, she can have the baby at the price of the deposit. Otherwise she'll probably have to have an abortion. That's the rule of our school. It varies, depending on the woman's work unit.

Me: What if the woman refuses to have an abortion?

FPPD: It depends. In our school she won't get the bonus for the year, and her promotion will be delayed a year or two. It might also affect her next raise. It's never happened in our department and only once or twice in the school. You don't have to worry about that, do you?

Me: $\quad$ For future reference only. By the way, how and where does one learn all these rules? Nobody's told me any of them. 
FPPD: We FPPDs usually just talk to those who get married before they are 23 years old. You were 25 when you came for the marriage certificate introduction letter, right? Most of you don't have the problem because when you graduate from college and come and teach here you're about 22 or older. Very few people get married immediately after they graduate. It takes about a year or two.

So I was making up the lesson I missed earlier. Finally, complete with our marriage certificate and pictures of myself and my husband, our Resident's Booklet, identification cards, stamped introduction letters, student card (for the prenatal education class) from the street council, and test result, we were honored with the most crucial document, the "Parturition Approval Certificate" - a plainlooking little red booklet, but the sole key that would open the door to all the health care programs for both the expectant mother and the baby to be born.

With the Parturition Approval Certificate in hand, I was guided to the gynecology department of the school infirmary, where I became a registered client for my prenatal and postnatal care. In my city, we have one prenatal checkup for the first trimester, then one each in the 16th, 20th, 24th, 28th, 30th, and 32nd weeks. After the 32nd week, we are advised to go for a checkup every week and come back whenever we feel uncertain about how we are. My colleagues and I went to the school infirmary for checkups before the 28th week and after that to the designated hospital where we were going to give birth.

Upon earning the Parturition Approval Certificate and the Pregnant Woman Physical Examination Card, one is all set. Now the expectant mother might as well take the chance to celebrate her legitimized expectancy with a delicious fatigue. By this time the first trimester is usually over.

"You've made it. I wouldn't be surprised if you had a miscarriage after what you've been through," said my mother-in-law, a good-natured, good-mannered lady with little sense of humor. "That would sure save on the family planning quota."

\section{Second Trimester-A Boy or a Girl?}

The initial chaos of activity and inner struggle gradually simmered down. I took the GRE in April and quit my second and third jobs, leaving just the translation job with the television station. I had my lightest workload ever, teaching eight instead of 20 hours of English a week, six hours of Chinese, and translating American cartoons. Being pregnant became the legitimate focus of my life, with one exception.

One day early in my second trimester, my department head ushered me to his office, looking very upset.

"Would you consider teaching more hours? We're really short of hands this year."

"Mr. Lu, if I ever have the right to say 'No' once in my life, I guess this is the time."

"Why are you so selfish? You're a model teacher."

"I think I know who I am, a person, a woman, and now a pregnant woman. I know my limit." He was not pleased. Neither was I.

"That's just the problem with female teachers. 'First she gets married, then she gets pregnant, then her child gets sick.' "

"You're right. I'm sorry, but if I had a wife to take care of pregnancy for me, I'd do anything you want."

I have always tried to work as hard as I could. Why not? It makes life rich and rewarding, and of course it makes my boss happy. I had earned my colleagues' 
respect. But it had stopped there. Before I became pregnant I used to go to the department office, pick up my mail, exchange smiles, and wave my colleagues good-bye because I could not afford the time to linger and gossip. Of course I was not well prepared to be part of the female department gossip anyway, because it was mostly about kids, prices, knitting experience, and the like, none of which I knew much about. Occasionally I felt excluded but mostly I decided I wanted to be more professional than they were.

Getting pregnant led me right into the group, and it turned out to be fun. I would teach my classes and visit the secretaries (we had three) and whoever else was hanging around. It never took too long for the conversation to be directed to me and my baby. Gradually, department social interaction became part of my life. My colleagues were very interested in my condition and seemed to have the answers to all of my anxieties.

Colleague A: With morning sickness that bad, your chances of having a girl are higher than having a boy.

Colleague B: No, it actually depends on what food you hanker for, whether you have a girl or a boy. Do you like tart food or hot and spicy food?

Me: $\quad$ Not much of anything. I don't have a good appetite at all.

Colleague A: That's bad. You should force yourself to eat. Otherwise your baby will be underfed. See, you're eating only a little, you're throwing up a little, and what's left? Eat a lot of good stuff. Walnuts are good for brain development and hair growth, shrimp and fish are good for overall development, apples are best for the skin. If you eat a lot of apples your baby will have beautiful fair skin. Come on, tell us if you like tart food or hot food.

Me: $\quad$ I used to like everything. Yogurt, fruit, corn cakes, Korean pickles [very hot and spicy], haws, frozen pears, and cold drinks. Now that I vomit so much, and hot food hurts my throat, I'm more cautious.

Colleague B: Good for you. Hot food means a girl and tart food means a boy.

Me: $\quad$ Don't give me that. I've heard too much of it. Hard to believe.

Colleague C: It's true. I used to love tart food, but after I got pregnant, I wouldn't even look at it. See, I had a girl.

Colleague D: I heard that if a pregnant woman longs for cold food, that means she's going to have a boy, because Chinese medicine says that fire, "yang," means "man," and water, "yin," means "woman." So if you want cold food all the time, it tells you there's too much yang and therefore too much fire.

Me: Is there anything I should be careful not to eat?

Colleague E: Definitely. Don't eat too many oranges or your baby will have very dark skin. Stay away from rabbit meat, otherwise your baby will have a hare lip. Corn cakes aren't good, either. Too coarse. Plus, that's peasants' food. Look, girl, you'll probably carry a baby once and only once in your lifetime. Take advantage of it and ask for something good. Ask for it. Men are very obedient when women get pregnant.

Me: $\quad$ That's mean.

Colleague X: No, it's not only for you. It's good for the baby. My mother says if a pregnant woman doesn't get to eat what she hankers for, you can tell later from something about the baby. It tells people you can't afford it.

Me: How can you tell?

Colleague X: Have you ever seen a baby with a birthmark or a very clear blood vessel on the nose between the eyes? That's it.

It turned out later that my baby did have one of those marks. After careful investigation, my colleagues decided that it resulted from my unsatisfied hankering for kiwi fruit. 
It seems every woman has a lot to tell about pregnancy, and all she needs is a foil, a pregnant woman. One day, when I was about four months pregnant and hardly showing, an old lady smiled at us when my husband and I were taking a walk.

The lady: You lucky young man, you will have a son.

My husband: How can you tell?

The lady: Look at your wife. Her hips tell more of her pregnancy than her belly and she has a bigger stride when she is on her left foot.

I had a strange experience involving my neighbor's mother-in-law which bothered me for a while. This neighbor had a newborn, hardly two months old when I was pregnant. Her mother-in-law came to cook and wash diapers. For quite a time the mother-in-law did not talk with anybody. Then one day after supper we were both in the kitchen washing dishes. She approached me with a hand ful of chopsticks. I was confused and just said, "Had dinner?" (a typical way of greeting people in China under informal circumstances). She said something I did not understand due to her extremely strong southern accent. I just smiled. She did not move, still holding her chopsticks in her hands. I was more confused. "Can I help you?" She tried very hard and gestured, "No, I can help you." I looked at her and smiled.

She divided the chopsticks between herself and me, three for each. Then she held one chopstick right in front of her and the other two parallel with each other, joined to the ends of the first one, and thus forming a half rectangle with the three chopsticks. She wanted me to do the same thing, and to place my half rectangle to meet hers and form one rectangle with the six chopsticks. I instinctively felt it was going to be about my baby-and this time it was some really weird magic.

"What is it?" I asked. She did not answer. Instead, she closed her eyes and started chanting. Finally she stopped and said something. I shook my head to indicate: "No, I don't understand." She held my hand in hers and traced the character "male" on it.

My curiosity was aroused. "How do you know?"

She asked me to put the chopsticks back into the rectangle position again and showed me how. It took a while but I understood her. Held the way I have described, my two parallel chopsticks and hers met somewhere in between, forming the rectangle. While she was chanting, the four chopsticks were supposed to move about a bit and finally the joining ones would miss each other and the rectangle would be broken. If they moved horizontally, it meant the baby would be a female; if the chopsticks moved vertically, a male.

I thanked her, feeling very strange. Later I talked with her daughter-in-law, who felt embarrassed and gave me her explanation of what had been going on.

"My mother-in-law is a very superstitious peasant. She did the same thing with me and told me it was a boy."

"You did have a boy, didn't you?"

"Yes, but it is all nonsense anyway."

"Do you know what she was chanting?" I asked.

"Good question. I never know what it is she says. It simply sounds like chanting."

A week later I went for my second regular checkup. The doctor is a friend of my mother-in-law (both my parents-in-law work at my university). After taking my blood pressure and weight, she put me on a bed and gave me the first ultrasound test. The "dong, dong, dong" of the baby's heart was like a drum, strong and regular. I felt so joyous and proud that teardrops trickled down my 
face. It all started to make sense. There was a life there and I was going to be a mother.

I went to the grocery store and got a whole bagful of high protein "goodies" and some fresh fruit to give my baby some extra nutrition. Watching me eating like "a starved tiger," my mother-in-law said it was going to hurt my stomach. I knew I was going to throw it all up and that was no fun, but if it was good for my baby, who cared? That was April 16, 1994.

A month later, as a regular procedure I was prescribed an ultrasound test and two other fetal tests at the district Maternity and Children's Hospital. My husband went with me. Both of us were curious about the sex of the baby, but we decided not to ask because we agreed we would not love a girl less than a boy and overt curiosity about the baby's sex would not make us look good.

The ultrasound doctor was a very serious-looking old man. That further discouraged our curiosity. It was very quiet and the air seemed frozen and still.

"Is it all right?" I asked.

"Oh, couldn't be better. You are more than halfway done, girl. By the way, congratulations!" My heart knew what it was but my ears had to hear it.

"What for?"

"It's a boy."10

I always thought I would love to have a girl and it would be a great joy to bring her up my own way. "A girl is a warm padded coat for the mother," as the old saying goes. After all, girls tend to be more attached to the parents and care more. Yet my Chinese rationale said that a boy is best as the first child because that takes care of everybody's expectations and concerns. ${ }^{11}$

\section{Third Trimester-Learning about Labor and Arranging the Hospital Stay}

When summer arrived I was in my third trimester. The main theme of gossip about a Chinese pregnancy-"boy or girl?"-was still in progress.

"It's a boy because you're not big."

"It's a girl because you're prettier. Boys make mom ugly, with freckles and a swollen face."

"It's a boy because you're still very active and flexible; with a girl you get lazy and clumsy."

"Boys are early birds. They always come before the due date; girls are lazy and they often arrive late."

I was fed up and told them that the ultrasound test showed it was a boy. That did not stop the discussion, which moved to how the baby kicked.

By this time, my anxiety about the labor was gradually overcoming the concern about the sex of the baby. No matter which it was, girl or boy, I wanted a safe and sound labor.

My apprehension built as the day drew near. 1 referred to the books on my shelf, two American books (in English), two Japanese books (in Chinese), and one Chinese book. The American books treated pregnancy, labor, and delivery more medically and technically. The Japanese books were very detailed, even down to every single item that should be packed and taken when one goes to the hospital. The Chinese book was very sketchy on both. Nonetheless, being Chinese I knew better than to trust books alone about such a complicated matter. Fortunately, my voluntary support group's discussion focus also tended in the same direction. I prepared the following task list based on the conversations:

1. Get in touch with my former student who works in the gynecology department of the hospital. I must have guanxi (personal connections) to ensure the treatment I want. First of all, in the midst of labor an unpleasant situation might eventuate if a 
woman does not have guanxi. Since the hospitals always have more patients than their capacity, knowing a staff member would ensure a nicer, less crowded ward. Second, having guanxi means the doctors and midwives would be more patient and encouraging during labor; otherwise it could easily turn to a process of "losing your sense of shame." And last, with guanxi the doctors would suggest a caesarean only when absolutely necessary, instead of merely for convenience.

2. Prepare gifts for any of the people to whom my guanxi person introduces me-the midwife-on-duty, the nurse, and so on. Give the gifts beforehand.

3. Try not to fuss or scream when in labor because the midwives and nurses have witnessed it too often to be sincerely sympathetic, or even to bother to pretend to be. Besides, the more I scream the more vaginal examinations they will make, and that can be very uncomfortable and embarrassing, especially when the doctor is a man.

4. Try to put off going to the labor room as long as possible because my family cannot be with me in either the labor or delivery room. If there are other women in the labor room and if one or more of them gets hysterical, that can be nerve-racking.

5. A caesarean does not hurt. It is just like a major operation and is done very frequently. It leaves an ugly scar. The cost ranges from $Y 1,000$ to $Y 2,000$.

6. A vaginal birth hurts and takes a while to recover from because the joints become loose, thus I would have to guard against cold and drafts (called "evil wind" in Chinese). A vaginal birth is the least expensive procedure. Y400 should take care of everything.

7. An episiotomy is the worst of all three. I would get the labor pain, the pain of the stitches, and the scar as well. I would have to guard against cold and drafts and take care of the wound at the same time to prevent infection. Increases the cost of delivery to something between Y600 and Y800.

8. There are three signs of labor: (a) either lower back pain (the labor sign for a boy) or a stomach ache (the sign for a girl)-it is coming soon; (b) reddish show [discharge]-it is probably in process. Get ready, take a shower, because it will be a month before my next shower; and (c) water sac breaks-it has started. Go to the hospital immediately.

A picture of labor was sketched before my eyes with none of the breathing skills I read about in the books nor anything nice about the baby, the excitement, the satisfaction, and the beautiful dreams I was having about him during those last days. These things I shared with my family and probably will share with my pregnant friends in the future.

\section{My Hospital and My Ward}

In 1993, 89.76 percent of the births in urban communities and 83.14 percent of the births in rural communities involved modern midwifery practice. In urban communities $\mathbf{4 4 . 9 2}$ percent of births took place in hospitals.

-Bian Su, Protect the Health of Women and Children

When I was 28 weeks pregnant, my parents-in-law took a hand in the hospital arrangements. After careful consideration they set about convincing my gynecologist at the school infirmary that I should give birth at a more prestigious hospital-and still get 80 percent reimbursement for the charges, although it would cost my employer twice as much as the designated hospital. Usually the doctors at the infirmary only sign such a permit for high-risk women. I was not on such a list. My mother-in-law used tactful manipulation and her connections in the infirmary to help persuade my gynecologist, explaining how much apprehension she felt as mother-in-law, how my case might be complicated (my last examination at the infirmary indicated a breech position), and that if something went wrong it would simply break her heart and destroy the family's hopes. The 
result was that the gynecologist at the school infirmary decided to transfer me to the hospital we requested instead of the designated one. ${ }^{12}$ I was surprised at how an inarticulate person like my mother-in-law could accomplish such a big task. All was arranged. We had a couple of guanxi connections in the better hospital; having the baby there would give me more confidence and help me to be more comfortable.

My due date was September 12,1994. I took two showers on that day and trimmed my bangs. I got all ready. I had a sleepless night, but it was not in vain. The reddish show started in the early morning of September 13. I checked into my carefully picked hospital six hours after the reddish show. It must have been "the season" because the hospital wards were all full. This was the first time ever in my life that I was put in a hospital ward, and I could not help being observant. There were seven other women in my ward (about 60 square meters). Everybody was referred to by her bed number. For example, I was put in bed number three, so I was "Bed Three." We never learned each other's names. Although there was a tag with our name and work unit on each of our beds, we never bothered. I spent two days before my delivery and four after it in the ward. There I experienced the most intimate of events and became a full member of the "women's club."

A friend of mine had long warned me that "giving birth to a baby is one of the most significant events in your life. Once you've undergone that, you're a real woman. You'll then be tough enough for any physical pain, and you'll probably lose your sense of shame."

It started to make sense after I moved into the ward. Among the eight of us, there was Bed One, an aeronautical engineer; Bed Two, a customs officer (import goods inspector); myself, Bed Three, a university teacher; Bed Four, a factory worker; Bed Five, a high school teacher; Bed Six, a saleswoman at a grocery store; and Bed Eight, a self-employed entrepreneur who was in the shoe-retailing business. I never learned much about Bed Seven except that this had been her third miscarriage. She walked in with her parents and her husband, pale as a piece of paper, and never talked to anybody in the ward; neither did any of the other family members. The only memory of her is a pair of beautiful eyes, so sad, so empty, so desperately helpless.

Bed Eight, the self-employed entrepreneur, was the oldest one among us. She was probably in her early forties. She was having her second baby, which is very unusual in present-day urban China. The reason she was enjoying this "privilege" (as we put it) or "misfortune" (as she called it) was that her husband (the second one) had never married before or had a baby, in which case, according to the family planning policy, they could have a child of their own besides her existing daughter from her first marriage. Her bed was opposite mine. Joined by my other ward-mates, she made my first night in the ward shockingly educational.

My first night at the hospital was her second night after her caesarean operation. I bet it hurt badly since she was groaning, whining, and cursing her husband all night long. And she was not the only one: Bed Four, the factory worker who had an episiotomy, after being awakened by Bed Eight, started weeping and crying. Bed One never tried to sleep. Her mother-in-law was helping massage and express her engorged breasts all night, and I heard her keep murmuring, "l'll never try to save money the rest of my life." Later I learned she believed the premature birth of the baby was caused by her riding on the same bicycle as her husband the day before. She told me,

It was about an hour's bicycle ride from my home to my mom's. We could have taken a taxi but I thought it would be too expensive, so we decided to ride his bike like we 
used to do. That night I went to the bathroom and saw blood everywhere. I thought the baby was gone. ... Now he's in that little special care box labeled "incubator." It's going to cost us a fortune. Fortunately, my work unit is very sympathetic, and hopefully they're going to pay a big part of it, but still... . I't's not the money. I wish I'd known better.

\section{My Labor}

The first night was neither quiet nor restful. All I wanted was to get it done and get out of there.

"Unfortunately," my doctor said, "your baby isn't ready yet. The cervix still isn't soft enough for him to pass." So the next morning my "responsibility team," made up of the department director, the ward doctor, and the doctor in charge of my bed, got together. They worked out the following plan to help accelerate my labor, since I had already told them that I did not want a caesarean:

1. They prescribed three days of a "cervix softening" injection.

2. If that did not work, they would use oxytocin, a hormone to induce contractions.

3. If my body did not respond to that, a water sac would be inserted into my uterus to help stimulate contractions.

4. The water sac works for most women, but since the doctors had just had their first failure of the year when another woman's water sac broke in her womb, they warned me of the possibility of a caesarean section anyway.

It took them a while to explain all this to me and I was overwhelmed. Since my guanxi, Professor $\mathrm{Li}$, was on the team I placed all my trust in her.

"Take me as your daughter, Professor $\mathrm{Li}$, and do whatever looks the best to you, please. I have no idea what is happening. All I want is a healthy baby and if possible, a still living me."

In the end, my baby knew best and never put me through all of the long list of medical tortures. After four injections regular contractions started, and by the morning of the 15th I was in serious labor. The director came in on her first visit of the day, ushered me to the "Internal Examination Room," gave me an examination, and smiled: "It'll be today, girl. It should be before 8:00 P.M. or even 6:00 P.M. We'll see."

It hurt really badly but I remembered my friends' warning: "Don't appear to be in pain or they'll keep giving you internal exams and that'll be no fun." Despite my "strong will" and "smiling face," by 10:00 A.M. they had given me my third internal examination and took me to the labor room. There I was separated from my family and put into a bed covered with a sheet of black rubber plus a comforter. In a very matter-of-fact tone the nurse told me to lie down and was gone. There were no other "screaming women" who "curse their men or threaten to commit suicide" (as my friend had warned me) in the room. I was the only one. About ten minutes later the nurse returned to shave me. That was very uncomfortable and I told her so. Her response was again matter-of-fact: "If this is uncomfortable, the labor will probably kill you." I shuddered.

The baby became more and more restless and with every contraction I clutched the bars of the bed head, bit my lips, and sweated badly. Then I thought of how one of the books said walking around and squatting help alleviate labor pains. Now one of the nurses was back in the room having her lunch. I asked if I could stand up.

She said firmly, "No, you can't."

However, the idea kept growing and finally I said, "I feel like going to the bathroom." 
"Pee or ... ?" I remembered from the books that "the onset of labor is similar to the urge of a bowel movement." So if I said "bowel movement" she would probably tell me that was normal and would not let me go.

"Pee," I said.

"Okay," she agreed.

The bathroom was at the other end of the three-room suite, with the delivery room in the middle. In the bathroom, I enjoyed the sweetest victory in my life, standing, squatting, and leaning against the wall. Before long, the nurse knocked on the door and shouted, "Come on out, if you don't want to have your baby in the bathroom."

I followed her out, walking back to the labor room through the delivery room, still secretly celebrating the ten minutes of freedom with a smile on my face. One of the midwives cleaning up the mess from the last delivery noticed me and said to the nurse: "This one isn't ready yet, look at that smile." I got the point. "So why don't you send me back to my ward?"

"Yes, we will," she said.

My ward-mates were all surprised to see me back, and I won myself one more hour of reunion with my family. They welcomed me with chocolate, boiled eggs, and Chinese dumplings, all of which were supposed to make me stronger so I could push better when the right time came.

At about 1:30 P.M. the director came to give me my fourth internal examination: "Bed Three, let's go to the delivery room again and get ready. It won't be too long and you never know when it will come." This time, my intuition told me, would be it.

As time passed, the pain became worse and worse, but I held it to myself and tried not to scream. Now my friend's prediction came true-the more fussy you are, the less sympathetic they are; the stronger you are, the nicer they are. The nurse, looking at the streams of sweat on my brow and the scratched comforter cover, said sympathetically, "Scream if it makes you feel better. Don't hold it in. Nobody will laugh at you. We're all women and know what it feels like."

I lost track of time and place and shed tears and sweat, but I did not scream. The attitude of the nurse no longer concerned me. As that last minute crawled near, something in me became distilled into a belief: "This is perhaps the ultimate ceremony of becoming a woman. Let's make it perfect and leave no regrets. We'll make it. Sure, if other people have made it."

Still under that dull white ceiling, still on that ugly bed. At some point (I do not quite remember when), that same nurse approached me with a king-size needle and ordered, "Part your legs." She broke the amniotic sac. I realized what was happening hardly a minute later, thanks to my friend who had told me about it. I would have been scared otherwise.

At three-something, the director, the ward doctor, and my doctor filed in. Two more of those wretched internal examinations were made. By this time I was at my wit's end.

"Professor $\mathrm{Li}$, please do something to end this."

"Oh, there's nothing I can do to make you feel better, girl. This is how you become a mother. You're already 5 fingers dilated and we don't want a caesarean after all this, right? All we need is a little more time. You'll make it. You're a very strong girl. Let's see how the baby is doing."

She monitored the heartbeat of my baby with an ultrasound and when the nurse told her my water sac fluid was a little dark, she got me an oxygen bottle. I couldn't stand it any more. Extreme pain paralyzed my usual caution and respect. With people still surrounding the bed, discussing the situation, I struggled to get up and said, "This is the time, let's go." 
I stumbled to the labor room with their help. I was by now completely exhausted and perhaps the weakest person in the world. They asked me to climb onto the delivery table on my own. It could have been a little more tolerable if they had not asked me to start to push immediately. Talk about "role distance." That was exactly what I felt. I wanted so badly to get it done and be done with it.

Now one of them said, "Stop pushing."

Then it was "Push," "Don't push," "Push." I was confused and they were frustrated.

"Silly girl, it's such a small baby-can't you do it by yourself? Either that or we'll give you an episiotomy."

"Whatever, as long as the baby's okay."

A midwife pushed on my belly very hard three times and the baby did not come. Then I felt something cutting me. It did not hurt. It was just the noise of it that I will never forget, like cutting up a chicken.

"Wah! Wah! Wah!" It must be the baby. The storm was over and all of a sudden I felt so light-hearted.

"A boy," said one of them.

"Thanks. Let me take a look at him."

Upside down. One of them held him high like that. I just remember the little red butt. "Boy," she reassured me. "Is he okay?" "Oh, yes, perfect."

Now they started to wash him, weigh him, and take all the measurements. Soon the director told me, "He's a 10 point baby." "What's that? Is it a good score?" I had no idea what it meant. "Oh, definitely, full score according to the Apgar system."13

The proud and contented feeling on having a full-score baby did not last long. I asked about the noise I heard a moment ago and was "reassured" that I had had an episiotomy. It was disappointing news.

"It's not a natural birth, after all. Why didn't I feel any pain when you cut me? Did you give me anesthesia?"

"No, the pushing numbs your muscles." Explaining the need for the cut, the older nurse said, "When we were young, we used to give birth on our own. Your generation doesn't exercise, doesn't do manual labor, doesn't have the muscles, I guess."

Somebody came and pressed my belly again. The result was what they called the afterbirth. I knew it was the placenta. I had read descriptions of placentas and how nutritious they are. Some people even told me that they are used in medicine, but I have not been able to verify that as fact or folklore.

"What are you going to do with it?" No answer. I remembered once using a very popular face cream called "placenta cream." Lying there, I felt sincerely sentimental about my placenta.

After a short preparation they started to stitch the cut. Never was I told that this would be the worst part. It went on and on and on, forever. This time, boy, did I scream!

I begged, "Could you please give me some anesthesia?" I had to repeat it a couple of times before one of them responded, "No, because the wound doesn't heal as well with anesthesia." "Why not?" "With anesthesia your muscles swell. Swollen muscles don't grow back the same way as they would otherwise."

Finally it was over. My baby was taken away without my noticing. Little did I know that I would not see him again for nearly a week.

I had to stay four more days in the hospital before the episiotomy stitches could be removed. The stay was eight days for a caesarean and two days for a natural birth. Mothers stayed in the same ward, while the newborns were kept in the nursery, on the same floor. They could only see their babies at the set nursing 
times: 8:00 A.M., noon, and 4:00 P.M. I never did get to see my baby, because Bed Eight and my gynecologist student told me that if I was able to hand-express my milk I had better not nurse, because all the breast-fed babies were put in a separate room. In that room there might be a higher chance of infection, with the mothers visiting back and forth to nurse. Besides, they said, the breast-fed babies were not fed as well as the bottle-fed ones who were fed in the nursery, because the breast-feeding mothers were only given a limited time to feed their babies. The hospital simply assumed the mothers had fed them well, whereas in fact the babies might never have had time to get to eat as much as the bottle-fed ones.

"The truth is," said Bed Eight, "very few moms have enough milk, those first couple of days."

Since I didn't want my baby to be underfed or infected, I did not get to see him until the day we left the hospital. Instead, I was treated like a baby by my own mom, my mother-in-law, my husband, and his aunts.

\section{Postpartum-Sitting Out the Month}

For about a month following delivery, Chinese women are typically confined to their own rooms. This is called zuo yue zi, or "to sit out the month." The length of confinement in China varies according to the sex of the newborn. In my part of the country, it is 28 days if it is a boy, because of the idea that recovery from giving birth to a boy is easier than with a girl, which takes 30 days.

Traditionally, the task of catering to the apparently fragile new mother and her baby falls onto the shoulders of the mother-in-law, although most women would feel more comfortable with their own mothers. The rationale behind this is that by giving birth a woman has added a person to her mother-in-law's family instead of her own mother's. Even today many women still recover with the mother-in-law's help, especially if they live together. Moving back in with the woman's own mother or having her own mother around the house too much can be well taken as a sign of bad relationship between the daughter-in-law and mother-in-law. Relatives and neighbors would usually gossip.

During that month the new mother is not supposed to leave the room, but if she has to, she should wear a hat, scarf, gloves, warm flat shoes, and a mask over her face to stay away from the cold, evil wind. Preferably she should lie in bed all day long and not walk around even indoors, since it causes pain in the back and sore feet in the future. There should be no washing of the face or hands, dishes or diapers, particularly not with cold water, because cold water causes wind to enter the body through the joints, orifices, and heels. If the baby is a girl, violation of the rules causes arthritis, asthma, and chronic aches and pains. If the baby is a boy, violation of the rules does not result in these symptoms. There is no brushing the teeth (causes toothache) or combing the hair (causes hair loss and pain), not to mention no taking a shower.

As for me, I did stay indoors, but I kept the windows and door slightly open all the time to get some fresh air. I did brush my teeth and wash my hands and feet, and I took a shower every day with all the doors, windows, and ventilation spots shut. I asked my husband to make some fruit drinks with our blender every day so that I could still get vitamins without chewing them and "hurting my teeth." I also asked my mother-in-law to put some vegetables in with the noodles I ate. I never stayed in bed all day long. Instead, I got up, got dressed, walked around the room, and did some reading or writing when my baby was asleep. When he woke up I played music for us both and danced with him in the room. I learned to change diapers. I found pretty much a "happy middle path" between tradition and reality despite all the criticism I received. 
A person I want to mention here is Ms. Wang, the cleaning lady at the hospital where I stayed who was later my breast-massage lady. When I was in the hospital, my roommates told me that our cleaning lady was actually a breastmassage lady in disguise. Breast massage for nursing purposes was not an officially recognized practice in my hospital. Ms. Wang, a retired factory worker, had through the years learned this skill. Her job in the hospital was cleaning the wards, but she really made her living and fortune by massaging. She and the other cleaning lady shared one job in two shifts. When Ms. Wang was on the night shift she would take up her real profession. The women liked her, needed her, and tried to protect her from the doctors and nurses, who would have fined her.

While I was staying in the hospital, my breasts started engorging on the second day after delivery and my mother tried to help with the hand-expressing. ${ }^{14} \mathrm{Ms}$. Wang kindly offered to teach my mom how to do it right.

On the ninth day after delivery, I started to develop little bumps and my breasts became sore. My husband thought again of Ms. Wang. He called her, and she came in and cured the trouble. The bumps were gone and milk came out in fountains. She earned our respect and a salary.

\section{Returning to the World}

In those days of pregnancy and labor, I was immersed in the world of women. Friendship and trust among my women associates grew with my unborn baby. For the first time in my life I owned no other identity besides the "woman" or the "pregnant woman" one. Now I am back in the "normal world" again, the world with men and women. I am once more the person I used to be, faced with a new version of my old dreams and ambitions, approvals and disapprovals, satisfactions and guilt.

-An excerpt from my journal

So sitting out the month-the longest month in my life-passed, and finally liberation day came. To be safer, we celebrated the full month on the 30th day instead of the 28th. The family and all our guests had a big banquet in a restaurant. My baby was also brought there for a brief show-off.

I was liberated from being overdosed with all the nice cares, from being treated like a fragile piece of china, and from having to observe all the "do's" and "don'ts." But life has not been the same ever since and I am no longer the same person, and I have noticed a change in the attitude and degree of my acceptance by both women and men.

My maternity leave ran from early July 1994, when the summer vacation started, all the way to early March 1995, when the spring semester began. I greatly enjoyed being around my baby, nursing and nurturing him, but by March I was ready to work, too. Two of my former employers, the university and the city government, badly wanted me back. By now I had also heard from the American graduate school where I had applied.

In May 1995, when I was offered a job abroad as interpreter for a local government delegation on its North America visit, I had to wean my baby at his eighth month. It was a hard decision, and it could have been worse if I had not had a very supportive husband and our understanding and helpful families. There was already quite a bit of gossip among my colleagues and neighbors about my "irresponsibility" toward my baby. People even teasingly pointed fingers in my face. Although a large number of urban women do decide to bottle-feed their babies in order to keep their figures, the tradition of "the longer the better" is still strong and can cause tremendously guilty feelings in many women. 
At the end of June 1995, I returned to my home city from my first trip abroad and started packing for the second trip. I had heard from my graduate program that I had obtained a good scholarship and a job teaching Chinese.

In some ways it was not an easy choice. Nonetheless, my families and I made it despite a lot of voices like that of my grandfather: "I never thought you could be such a cruel woman. You are too ambitious as a woman and unqualified to be a mother."

In the course of time, with the help and support of my family, I have managed to juggle my multiple social and family roles. This has not been without difficulty, but the resulting sense of satisfaction and confidence is indeed rewarding.

\section{Conclusion}

The one-child policy contradicts traditional Chinese values. Chinese people have always preferred large families because of China's historical labor-intensive agrarian economy. In such a society, the family is also the basic economic unit of production, and the number of children-especially male children-is seen as a positive predictor and indicator of the family's production capacity.

Since the one-child policy, "Population has been raised insistently not just as a problem but as a principal causal factor in China's failure to progress in history." China's population policy is a "test of national will, a race against time and history" (Anagnost 1995:24-25).

In 1991, it was mentioned in official speeches celebrating the 70th anniversary of the founding of the CСP (Chinese Communist Party) that Mao Zedong himself had said in 1957 that the lack of a birth policy was a form of "anarchism." However ironic, given Mao's strongly pronatal stance during the 1950s and his persecution of the noted demographer Ma Yinchu for advocating birth control, the attribution indicates the degree of governmental control over childbirth in China (see Anagnost 1995).

The politicization of pregnancy and childbirth has caused tremendous controversy among foreign scholars and many Chinese, especially the rural agrarian population. The conflict is between what Max Weber called "tradition" and "rationality." The rationalization of society on the way to modernization is unavoidable; the association of population control with national growth is not uncommon. This is how the world has come to witness the institution of family, as a productive and reproductive unit, stringently bureaucratized in China.

Properly educated and appropriately socialized, I joined most Chinese with similar experiences of the Chinese social system in painlessly digesting the rationales behind the one-child policy. However, we experienced frustration with the way the political and medical institutions manipulated our personal lives.

The rationalization and bureaucratization of marriage and childbirth is clear. Needless to say, pregnancy and childbirth, together with other significant life events, offer yet another merging of society and self, of public/political and personal/private concerns in a planned society like China.

Despite the enormous role played by the state in marriage, pregnancy, and childbirth, information on sex and sex-related roles is scarce, incomplete, and inaccurate. Such knowledge, even in ambiguous or technical terms, is only minimally transmitted by the established political, educational, medical, and family institutions. And when the knowledge is transmitted, as on such rare occasions as marriage registration day (when the couple views the sex education video), it is under the mask of contraception to promote the government family planning policy. 
The only legitimate channel for obtaining such information is through legal marriage. This is where phenomenological understanding is of great relevance. Abundant information on sexuality and childbirth does exist in China. However, this world of knowledge is not accessible to a young woman until her situation is labeled appropriate: initially, when she begins the formal procedures culminating in legal marriage, and, more importantly, when she becomes pregnant. An intriguing interplay between subjectivity and objectivity is thus observed at its fullest display. Although "appropriate situation" - that is, the timing of sex education-is a culturally relative and often subjective determination, the definition of this situation in China is formally and objectively imposed in keeping with the taken-for-granted social reality that, unfortunately in this circumstance, includes the long-standing Chinese tradition of premarital abstinence. What follows is the irony seen between the lines of my narrative - one does not learn until it is too late. And what one does learn may or may not be scientifically credible, especially knowledge of the more gender-specific experiences such as pregnancy and childbirth. There seems to be more reliance on folk wisdom than on contemporary science.

However, there is plenty of evidence that this situation is not going to last. With the Chinese economic "open-door" policy, Western technology, values, and beliefs are claiming more and more Chinese minds, especially among the young. As the boundaries of traditional values, norms, and beliefs erode, Chinese interpretations of situations relating to sexual knowledge are less stringently bound by the rigid criteria described in the preceding narrative. Intimate knowledge regarding sex, conception, and contraception is becoming more accessible through unofficial channels and is expected to be eventually more accessible through official channels.

Still, the current unavailability of information regarding sex, conception, and contraception results in much ambiguity in role expectations and thus the obstruction of identity construction. This is particularly true for young women in Chinese society, who are expected to endure dramatic identity transformations in a very limited time span.

For professionally ambitious women, the situation is particularly complex. On college campuses, romantic relationships are discouraged and routinely treated with contempt, since one's role as a student is not supposed to overlap with any other roles except those within the kinship system. But a college-educated woman has to experience accelerated identity transitions over a two-to five-year period-from the "pure" girl who is her parent's child, her siblings' sister, and her teacher's student, to a mature woman, a wife, a mother, a daughter-in-law, and a professional.

Sexual activity is the key concept in this process of identity transition. With dating and marriage, the young Chinese woman loses her sexual innocence, a virtue highly valued in Chinese society. This puts her in hazardous terrain, since full membership in the sorority of mature women is achieved only upon becoming pregnant and giving birth to a child. The rite of passage to the mature female gender role in Chinese culture, as in many other traditional cultures (Oakley 1980), is pregnancy and childbirth.

Once pregnant, her destination-the new role of mother and mature woman-prescribes that she no longer be alone in her search for mature femininity. During this lengthy rite of passage, her female support group and its activities take many forms. Family members, colleagues, neighbors, personal friends, hospital ward-mates, staff, and even passersby have something to share and contribute. The collective effort and commitment of her female associates 
constitute the socialization process that transforms and shapes the pregnant woman for her new status: mature woman.

The patriarchal nature of Chinese society is such that a woman, in conformity with long-standing tradition, can only pursue her femininity by marrying. Getting pregnant clears her path, but only in the light that other mature women shed with their knowledge and experience can she truly attain femininity. Nevertheless, awaiting her is the patriarchal social reality. Given the role conflict between the traditional patriarchal expectations of the wife-mother and the contemporary possibility of becoming an educated professional, she has to constantly struggle for even the illusion of paradise.

In presenting this personal narrative, I do not intend to generalize about all Chinese women, rural or urban. It is my hope, however, that by combining the individual pieces of the puzzle the reader will find that a more inclusive portrait of women in Çhina will emerge.

\section{Notes}

Acknowledgments. I would like to acknowledge Patricia Beaver, Department of Anthropology, Appalachian State University, whose encouragement, input, and assistance have been essential to both this work and my personal and professional development; Dorothea Martin and Melissa Schrift, who commented on an earlier draft; and the constructive suggestions of anonymous reviewers. An earlier version of this article was presented at the annual meeting of the Southeast Asian Studies Association, Knoxville, Tennessee, January 1996.

1. See also Bergum 1989, Breen 1975, Chodorow 1978, Collins and Dunkel-Schetter 1993, Dye 1986, Eakins 1986, Hees-Stauthamer 1985, Kahn 1995, Levesque-Lopman 1988, Lott 1981, Meltzer 1981, Phillsbury 1982, and Raphael 1975.

2. See, for example, Anagnost 1995, Banister 1987, Chu 1993, Furth 1987, Huang 1990, Johnson 1975, Su 1995, and Wolf 1985.

3. See, for example, Aird 1990, Mosher 1993, Smith and Ping 1995, and White 1994.

4. Among other factors that make a day auspicious, the most popular is an even-numbered date (both the number of the month and that of the date) in the lunar calendar. Many Chinese choose such a day for weddings.

5. "It" would be a good translation for "him/her" as the pronoun is the same in Chinese.

6. In China, most households have only one water tap-cold water. We routinely have to boil our own hot water in kettles a couple of times a day.

7. Except for some modern office buildings in a handful of major cities, most Chinese buildings are not air-conditioned. The quality and efficiency of the heating systems vary a great deal, too. Up north, people have to put on layers of clothes to stay warm both indoors and outdoors.

8. Traditionally, Chinese do not celebrate Christmas; but with the importing of Western culture, many young Chinese today, especially students at all levels, do exchange cards and gifts, and throw parties around Christmas.

9. About one month later, Lei was pregnant with her third baby, who was born three weeks later than mine. The latest I have heard is that she is now the mother of four.

10. Actually, the Mother and Child Health Care Law, which was adopted by the National People's Congress in 1994, had already banned unauthorized sex identification tests of fetuses (China Today 1995). So doctors do not usually tell the parents the sex of the baby.

11. I thought this great enthusiasm over the birth of a boy was unique to the Confucian tradition in China: "Noble the man, humble the woman." Interestingly, Oakley writes that "most women have definite ideas about what sex they want the baby to be. It is a common finding of research on parents' sex preferences that boys are more popular than girls; this is especially the case with first babies" (1979:118).

12. In China, the government pays 80 percent of all hospital bills (medical expenses/maternity expenses, et cetera) for state employees. In fact, the ultimate budget is 
the responsibility of the specific work unit the person is with, and that is why the level of charges is taken into consideration when it comes to the choice of a designated hospital.

13. The Apgar scoring system "provides a standardized means by which birth attendants can assess the baby's condition at birth. Signs rated at two points each on a preprinted chart are skin color, muscle tone, breathing attempts, heartbeat, and response to stimuli, such as a touch or a pin-prick. Ten is the highest obtainable score" (Davis-Floyd 1992:135).

14. It is usually either the mother, the mother-in-law, a woman relative or friend who has had children, or the husband who does the massage.

\section{References Cited}

Aird, John S.

1990 Slaughter of the Innocents: Coercive Birth Control in China. Washington, DC: American Enterprise Institute for Public Research Press.

Anagnost, Ann

1995 A Surfeit of Bodies: Population and the Rationality of the State in Post-Mao China. In Conceiving The New World Order. Faye D. Ginsburg and Rayna Rapp, eds. Pp. 22-41. Berkeley: University of California Press.

Banister, Judith

1987 China's Changing Population. Stanford, CA: Stanford University Press.

Beaver, Patricia, and Melissa Schrift

1994 Chinese Women Intellectuals: Courting in the 1990s (Strange Women, The Problem of Da Gu Niang). Paper presented at the Southeast Asian Studies Association conference, Harrisonburg, VA, January.

Bergum, Vangie

1989 Woman to Mother: A Transformation. Grandy, MA: Bergin and Garvey.

Breen, Dana

1975 The Birth of a First Child: Towards an Understanding of Femininity. London: Tavistock Publications.

China Today

1995 Prenatal Sex Test Ban for Beijing. China Today 7: 3.

Chodorow, Nancy

1978 The Reproduction of Mothering: Psychoanalysis and the Sociology of Gender. Berkeley: University of California Press.

Chu, Cordia M.

1993 Reproductive Health Beliefs and Practices of Chinese and Australian Women. Taipei: Population Studies Center at National Taiwan University.

Collins, Nancy L., and Christine Dunkel-Schetter

1993 Social Support in Pregnancy: Psychosocial Correlates of Birth Outcomes and Post-

partum Depression. Journal of Personality and Social Psychology 65(6): 1243- 1258.

Davis-Floyd, Robbie

1992 Birth as an American Rite of Passage. Berkeley: University of California Press. Dye, Nancy S.

1986 The Medicalization of Birth. In The American Way of Birth. Pamela S. Eakins, ed.

Pp. 21-47. Philadelphia: Temple University Press.

Eakins, Pamela S., ed.

1986 The American Way of Birth. Philadelphia: Temple University Press.

Furth, Charlotte

1987 Concepts of Pregnancy, Childbirth, and Infancy in Chi'ing Dynasty China. Journal of Asian Studies 46 (February):7-35.

Hees-Stauthamer, Jedlemieke C.

1985 The First Pregnancy: An Integrating Principle in Female Psychology. Ann Arbor, MI: UMI Research Press.

Huang, Shumin M.

1990 Folk Reproduction Medicine in North China: The Cultural Constructs of Pregnancy, Delivery and Post-Natal Care. Bulletin of the Institute of Ethnology Academian Sinica 70:13-38. 
Johnson, Elizabeth

1975 Women and Childbearing in Kwan Mun Hau Village: A Study of Social Change. In Women in Chinese Society. Marjorie Wolf and Roxane Witke, eds. Pp. 215-242. Stanford, CA: Stanford University Press.

Jordan, Brigitte

1983 Birth In Four Cultures. Montreal: Eden Press.

Kahn, Robbie P.

1995 Bearing Meaning: The Language of Birth. Urbana and Chicago: University of Illinois Press.

Kay, Margarita Artschwager

1982 Anthropology of Human Birth. Philadelphia: F. A. Davis.

Leifer, Myra

1980 Psychological Effects of Motherhood: A Study of First Pregnancy. New York:

Praeger.

Levesque-Lopman, Louise

1988 Claiming Reality: Phenomenology and Women's Experience. Totowa, NJ: Rowman and Littlefield.

Lott, Bernice

1981 Becoming a Woman: The Socialization of Gender. Springfield, IL: Charles C. Thomas.

Martin, Emily

1987 The Woman in the Body: A Cultural Analysis of Reproduction. Boston: Beacon Press.

Ma Yinchu 1957 New Demography. People's Daily, July 5: 1.

Meltzer, David 1981 Birth: An Anthology of Ancient Texts, Songs, Prayers, and Stories. San Francisco: North Point Press.

Mosher, Steven 1993 A Mother's Ordeal (The Story of Chi An): One Woman's Fight Against China's One Child Policy. London: Warner.

Oakley, Ann

1979 Becoming a Mother. New York: Shocken Books.

1980 Women Confined:Towards a Sociology of Childbirth. New York:Shocken Books.

Phillsbury, Barbara

1982 "Doing the Month": Confinement and Convalescence of Chinese Women. In Anthropology of Human Birth. Margarita A. Kay, ed. Pp. 119-146. Philadelphia: F. A. Davis.

Raphael, Dana

1975 Being Female: Reproduction, Power, and Change. The Hague: Mouton.

Smith, Herbert L., and Tu Ping

1995 Determinants of Induced Abortion and Their Policy Implications in Four Counties in North China. Studies in Family Planning 26(5):278-286.

Su, Bian

1995 Protect the Health of Women and Children. Women of China 8 (August):22-24.

White, Tyrene

1994 The Origin of China's Birth Planning Policy. In Engendering China. Christina K. Gilmartin and Gail Hershatter, eds. Pp. 250-278. Cambridge, MA: Harvard University Press.

Wolf, Margery

1985 Revolution Postponed: Women in Contemporary China. Stanford, CA: Stanford University Press. 